\title{
Poderes de perversión: la femme fatale colonial de la narrativa española del siglo $X X^{2}$
}

\section{Powers of Perversion: the Colonial Femme Fatale on the 20th Century Spanish Narrative}

\begin{abstract}
RESUMEN
Este artículo se propone analizar el comportamiento de uno de los arquetipos clave de la narrativa colonial española: la femme fatale marroquí, una odalisca envuelta en velos que se halla puertas hacia dentro de los harenes imaginados por las autoras. El propio Edward W. Said aseguró que no existía ninguna posibilidad de representar a Oriente sin prejuicios, porque Oriente ni siquiera existía y todo conocimiento sobre él era una quimera políticamente interesada, un tropo (2003). Sin embargo, también insistió en que lo único que le quedaba al intelectual era la denuncia y el intento de representar al objeto con mayor fidelidad (1996). Justo es lo que estas páginas se proponen, colaborar en la representación más fiel del objeto, mediante el análisis de la construcción de la femme fatale marroquí. La metodología empleada está fundamentada sobre los principios rectores del análisis desde la perspectiva de género, los estudios culturales y las teorías postcoloniales.

Palabras clave: femme fatale, mujeres escritoras, arquetipos femeninos, literatura española, narrativa colonial, alteridad.
\end{abstract}

\section{Abstract}

This paper focuses on the behavior's analysis of one of the capital archetypes of the Spanish colonial narrative: the femme fatale. An odalisque wrapped in veils which, indoors the harems, have been imagined by her writers. Edward W. Said assured that there was no possibility of representing East without prejudices, because East did not even exist and all knowledge about it was a politically interested chimera, a trope (2003). However, he also insisted that the only thing remained to the intellectual was the denounce and the attempt to represent the object with bigger fidelity (1996). It is just what these pages propose, to collaborate in the most faithful representation of the object, by analyzing the construction of the Moroccan femme fatale. The applied methodology is based on the guiding principles of the analysis from the perspective of Gender, Cultural Studies and Postcolonial Theories. Keywords: Femme Fatale, Women Writers, Female Archetypes, Spanish Literature, Colonial Narrative, Otherness.

\section{SUMARIO}

1.- Introducción. 2.- Poderes de perversión: música, baile, sexo y cuentos al amor de la lumbre. 3.- La profesionalización de la mujer fatal: el tópico desgastado como contradiscurso. - A modo de conclusión: el deber de asesinar criaturas literarias. - Referencias bibliográficas.

1 Universidad de La Laguna, yasminaromero@hotmail.com

2 Este trabajo forma parte del Proyecto I+D «Justicia, Ciudadanía y Vulnerabilidad. Narrativas de la precariedad y enfoques interseccionales» (FFI2015-63895-C2-1-R) financiado por el Ministerio de Economía y Competitividad del Gobierno de España. 


\section{Introducción}

Pensar en colonias españolas durante el siglo XX es evocar, principalmente, Marruecos. La pérdida de la mayoría de su imperio americano, en especial tras la derrota contra los Estados Unidos en 1898, llevó a España a centrarse en sus dominios africanos, la llamada Guinea Española, Ifni, la provincia del Sáhara -que desde 1975 forma el territorio disputado del Sáhara Occidental-y el Protectorado Español de Marruecos que duraría hasta 1956.

La ocupación de Marruecos hizo que muchas familias españolas sintieran interés por lo que sucedía al otro lado del Mediterráneo, fue el nuevo imperio español. Pocas de ellas no tenían un padre o un abuelo que hubiera participado en cualquiera de las diversas guerras hispanomarroquíes y que contara anécdotas del norte de África, de sus gentes y sus costumbres. Este es uno de los motivos por el que cientos de escritores y de escritoras publicaron sus novelas y relatos en el siglo XX con el escenario marroquí de fondo porque, de alguna manera, Marruecos ocupó su propio lugar en el imaginario compartido de la España del siglo pasado. Pero también hubo otro motivo, desde un punto de vista más profundo e instintivo, porque la presencia del imperio en el imaginario español -ya fuera el temprano imperio derivado de la conquista y colonización del llamado Nuevo Mundo o el que se originara justo cuando se perdió este, el africano-, han pervivido en la memoria colectiva, es la «conciencia imperial» de la que nos hablara Edward W. Said $(2003,2012)$ que ha permeado nuestras realidades más cotidianas, también las literarias ${ }^{3}$.

Hay más de doscientas novelas que tienen a Marruecos como escenario literario en la pasada centuria (López García, 1994; Carrasco González, 2009) y no dejan de publicarse en la actualidad más títulos, como la conocida novela El tiempo entre costuras (2009) de María Dueñas o la finalista del Premio Planeta Niebla en Tánger (2017) de Cristina López Barrio. Un conjunto literario que no ha recibido suficiente atención crítica, sobre todo por parte del campo de los estudios de género y postcoloniales y que puede concebirse en sí mismo como una verdadera narrativa colonial, esto es, aquella «manera de narrar sobre países alejados sin pertenecer al pueblo natural de ellos y con un sentimiento o mentalidad mayor o menor, de alteridad» (Carrasco González, 2009: 9).

Esta investigación tiene como fuentes primarias esa narrativa española de ficción de tema marroquí pero sólo la publicada durante el siglo XX y escrita por mujeres. La elección de las fuentes primarias vino motivada por la ausencia de una monografía o estudio cuyo corpus literario atendiera a estas escritoras españolas que los catálogos generales omiten o señalan tangencialmente, de las que

3 Con realidades cotidianas me refiero a estaciones de metro como la de Estrecho o Tetuán en Madrid o a la plaza de Tetuán en Barcelona e, incluso, aquellas viejas tiendas de «ultramarinos» que, originariamente, vendían productos alimenticios importados de las antiguas colonias, de territorios de «ultramar», como café o especias. La investigadora Alda Blanco los denomina «lugares de memoria» y, en su opinión, son menos frecuentes en España si los comparamos con los muchos de Francia o Inglaterra, otras antiguas potencias coloniales europeas. Véase BlANCO, Alda (2012). Cultura y conciencia imperial en la España del siglo XIX, València: Universitat de València. 
no hay análisis de conjunto, ni estudios críticos y, por supuesto, no se reeditan ya sus textos. Por otro lado, se buscaba comprobar si estas mujeres españolas eran mantenedoras de tópicos, estereotipos y atributos negativos relacionados con la identidad normativa de otras mujeres, en este caso de aquella de contextos árabeislámicos, en particular, de la marroquí. Fue así como se rescató del olvido - muchas de ellas lo estaban-, a veintidós autoras ${ }^{4}$ y sus veintidós novelas y cuarenta relatos de ficción ${ }^{5}$. La primera de las novelas publicada por Carmen de Burgos, En la guerra (1909) y, la última de ellas, por Concha López Sarasúa, ¿Qué buscabais en Marrakech? (2000), en medio, casi cien años de escritura, más de cinco mil páginas y sesenta y dos tramas diferentes en las que no se ha considerado pertinente ahondar en su argumento ni contextualizar en su gestación factual, debido a que el propósito de este trabajo no han sido las mujeres marroquíes «reales» que habitaron durante el siglo pasado al otro lado del Estrecho, sino ofrecer una imagen de conjunto sobre las representaciones de un objeto literario totalmente imaginado -e, incluso, sus no representaciones, omisiones y disimulaciones- en un discurso orientalista de textos narrativos españoles escritos por mujeres. Un arco temporal de casi cien años que devuelve un personaje-tipo, "cliché de la historia colonial» (Martín-Márquez, 2011: 157), al que no ha afectado prácticamente, como veremos, el devenir histórico de sus autoras sino que se ha mantenido inmutable desde aquellos harenes prototípicos evocados paradigmáticamente por cuadros como $\mathrm{El}$ baño turco (1862) de Dominique Ingres.

A la luz de lo anterior, el presente artículo se propone el análisis del comportamiento de uno de los arquetipos clave de esta narrativa colonial, la femme fatale marroquí que, además de compartir los rasgos habituales del personaje-tipo -ampliamente estudiado en la cultura universal (Bade, 1979; Dijkstra, 1986; Bornay, 1990) - tiene la particularidad de estar envuelta en velos y hallarse puertas hacia dentro de los harenes imaginados por las autoras. Una suerte de sherezade marroquí que participa de las prácticas representacionales orientalistas vertidas por las autoras españolas y que, como veremos, no sólo tienden a no ser muy positivas, sino que son enormemente reduccionistas y falseadas. La mujer fatal marroquí se constituye como una diferencia que perturba el orden identitario occidental y que, al mismo tiempo, limita sus contornos. Así, este personaje literario es todo lo que no quiere ser el sujeto español que lo construye, las autoras, por lo que lo expulsan de la representación de su propio «yo» y lo convierten en «abyecto», en el sentido dado por Kristeva (1980).

El propio Said aseguró que no existía ninguna posibilidad de representar a Oriente sin prejuicios, porque Oriente ni siquiera existía y todo conocimiento sobre él era una quimera políticamente interesada, un tropo (2003). Sin embargo,

4 Carmen Martel, Concha López Sarasúa, Encarna Cabello, Marisa Villardefrancos, Regina Flavio, Concha Linares-Becerra, Mari Paz Estévez de Castro, Cristina Fernández Cubas, Carmen de Burgos, María Charles, Carmen Martín de la Escalera, María Teresa de Jadraque, María Viñuelas, Blanca Ibáñez Blanco, Josefina María Rívas, Rosa de Aramburu, María Adela Durango, Margarita Astray Reguera, Rosa María Aranda, Julia María Abellanosa, Carmen Nonell y Dora Bacaicoa.

5 En la bibliografía final pueden consultarse todas estas obras y las ediciones usadas para este trabajo. 
también insistió en que lo único que le quedaba al intelectual era la denuncia y el intento de representar al objeto con mayor fidelidad (1996) ${ }^{6}$. Justo es lo que estas páginas se proponen, colaborar en la representación más fiel del objeto, al poner al descubierto el andamiaje orientalista que sostiene a la femme fatale marroquí. Sólo de esta manera se podrá acabar con esta representación literaria, aunque como declaró Virginia Woolf, desarticular arquetipos es especialmente complejo, su naturaleza ficticia les es de gran ayuda, ya que «resulta mucho más difícil matar a un fantasma que a algo real» (2010: 214).

Finalmente, y en consecuencia, la metodología empleada está fundamentada sobre los principios rectores de la perspectiva de género, los estudios culturales y las teorías postcoloniales. Tres teorías que se distinguen por hacer uso de una lectura ideológica de la cultura al mismo tiempo que, como revelara Culler, tienen en común procurar demostrar que lo que damos «como de sentido común es, de hecho, una construcción histórica» (2014: 15).

\section{Poderes de perversión: música, baile, sexo y cuentos al amor de la lumbre}

La femme fatale de la narrativa española de tema marroquí es una mujer sensual, joven, bella, morena y cargada de joyas. Un personaje literario que las escritoras españolas imaginan utilizando su belleza, sus ropas y sus maquillajes para atraer a los hombres, pobres víctimas de sus artimañas. Vladimir Propp señaló que una de las funciones que tiene el malo en los cuentos -como se ha señalado, la otredad marroquí es la facción perversa en esta narrativa colonial-es «intentar engañar a su víctima para apoderarse de ella o de sus bienes» (2014: 42). Así, en consonancia con los cuentos tradicionales, y la literatura occidental en general, esta figura literaria femenina es de aparición habitual en la narrativa de tema marroquí, normalmente como antiheroína y presentando a las mujeres como trampas en las que caen los hombres, porque son abyectas y lo abyecto, nos advertía Kristeva «está emparentado con la perversión» (1980: 25).

No cabe duda, este personaje literario es conocedor de sus «poderes de persuasión, que pone a prueba con insistentes zalamerías hasta lograr su propósito» (López Sarasúa, 2002: 19). Le dice una joven marroquí a un médico español al que intenta manipular en la novela Tebib (1945):

- Me gustas; me gustas mucho.

- Pues tú a mí, no.

- Ya te gustaré. (Aranda, 1945: 64)

Y sabe que le gustará, porque utilizará distintos ardides entre los que se encuentra el cante, la música de los instrumentos que tañe, el baile, su oratoria e incluso sus artes amatorias.

6 Y es aquí donde cae en la trampa de su propio discurso: si el objeto puede ser representado con mayor fidelidad es que existe realmente un Oriente implícito, al menos, en la obra de Said, algo que a muchos críticos les ha parecido paradójico y contradictorio (Clifford, 1988) 
Así, estas seductoras marroquíes «tocaban derbucas y tañían los tamboriles que convierten cada hogar musulmán en un lugar de fiesta» (Martín de la Escalera, 1945: 29). En la estampa de ese pintoresquismo exótico se las describe cantando con «VOz timbrada y rica de matices [...] una canción dulce y sugerente» (Charles, 1993: 101) o «a media voz una canción somnolienta y nostálgica» (Martín de la Escalera, 1945: 69) mientras el resto de odaliscas imaginadas -no olvidemos que en los harenes no hay sólo una- «la corean repitiendo un estribillo que debe de ser malicioso a juzgar por los gestos y sonrisas con que lo acompañan» (Charles, 1993: 101).

También esta mujer fatal tañe instrumentos como derbukas ${ }^{7}$, laudes, panderetas, tamboriles e, incluso, pianos y violines. Alrededor de ella siempre hay muchos instrumentos musicales, también lo evidenció así la pintura orientalista. Algunos son improvisados y poseen una extraña atracción, como los cojines que se golpean con los dedos "como si fuera un derbuca» (Martín de la Escalera, 1945: 69) o las bandejas empleadas a modo de pandero o tam-tam (Flavio, 1938: 66) y es que se asegura que «el sentimiento melódico era innato en aquella raza de acusadísima personalidad» (Flavio, 1938: 67), incluso cuando hacen sus quehaceres domésticos acompañan «su tarea con una estridente canción de ritmo salvaje» (Martín de la Escalera, 1945: 94). Este personaje marroquí cantando y sacando sonidos armónicos de cualquier instrumento recuerda el papel esencial que desempeña la música en el imaginario orientalista donde es popular su poder para encantar y, también, evoca el mito de Ulises de manera irremediable y el canto de las sirenas. Esta femme fatal representa el espejismo, el hechizo que aparta al marino de su ruta y que lo hace estrellarse contra las rocas. Hermosa, joven, morena, seductora y dominadora del hombre debido a la debilidad sexual que siente hacia ella, logra empujarlo a hacer cosas que pueden perjudicarle. Por ejemplo, llevarlo a la ruina económica: «Vete, mala mujer, engendro del diablo, perro que me arruinas malgastando» (Martín de la Escalera, 1945: 157) o, sin más, a su propia aniquilación: «Sabía que existía el peligro. Eres demasiado bonita; pero ya no volveré más. No quiero verte. No quiero bordear el precipicio de tus miradas» (Aranda, 1945: 202).

Pero aún hay más. En este ambiente de seducción esta cautivadora mujer imaginada no sólo toca instrumentos sino que baila de forma «cadenciosa y lúbricamente, llevando en sus caderas vaivenes de lujuria» (Ibáñez Blanco, 1956: 60) o, presas del atávico atractivo de lo oriental, «como si la mitad de su cuerpo, de cintura para abajo, estuviese poseído por algún duende obsceno» (López Sarasúa, 2002: 173). Todo forma parte de la magia de la ensoñación arabizante que busca complacer al espectador y que no difiere de las danzas supuestamente orientales que ha difundido la industria hollywoodiense: «un baile hecho ex profeso para turbar a quienes lo contemplaban» (Estévez de Castro, 1954: 12), es decir, excitando a los hombres pero sin intención de satisfacerlos dado que deben permanecer inactivos 8 :

7 Instrumento parecido a la zambomba, se ha encontrado transliterado de otras maneras como derbuca, darbuka o darbuca.

8 Rana Kabbani considera que esta es una de las diferencias fundamentales de la supuesta danza oriental retratada en las artes europeas frente a los bailes supuestamente autóctonos del viejo continente. Dice así, "Although the dance in European literature also has sexual undertones, the man in it is active participant, rather than voyeur (see Madame Bobary, Anna Karenina, Tess of the D’Urbervilles)». (2008: 230) 
Una danza de giros suaves, lentos, cadenciosos, llenos de ensoñación y de encanto, de matices exquisitos, en los que se estremecía el cuerpo núbil de la danzarina al interpretar los sentimientos del amor, de la pasión, que a veces convertía su bailar, lento y acompasado, en un torbellino de tules que revolotean a su alrededor como llamas devoradoras de su juventud (Estévez de Castro, 1954: 12).

Estos bailes reciben múltiples denominaciones, entre ellas «la danza del amor» (Ibáñez Blanco, 1956: 60), «danza ritual del desierto» (Estévez de Castro, 1954: 12) o «danzas morunas» (Durango, 1943: 23). En lo que respecta a la técnica, la mayoría de las veces, aunque no se especifique así, se describe la popular danza del vientre.

La mujer fatal ha estado asociada de modo habitual al baile, recordemos la danza de Salomé que terminó con la decapitación de Juan Bautista. Sin embargo, a pesar de esta característica habitual asociada al personaje-tipo (Dijkstra, 1986: 243 y ss.), los bailes y danzas han sido descritos siempre como alegorías de todo oriente, no sólo de Marruecos, como ha demostrado con abundancia la pintura orientalista del siglo XIX.

Muy interesante entre los poderes de atracción y perversión de esta representación literaria se halla, también, la facultad de cuentacuentos, igual quela original Sherezade: «¿Quieres que te cuente la historia prometida?» (Martín de la Escalera, 1945: 75). Iasmina es una de estas relatoras de la que se dice que embellece con maravillosas historias la vida (1945: 83). También Fettom que «según sus amigas, podría estar hablando durante cuatro lunas sin repetir una misma narración» porque posee un arsenal de historias amplísimo que «había heredado de su madre», un verdadero «stock de cuentos que hacía agradable la reunión de las azoteas» (Aramburu, 1937: 80).

La destreza innata en el arte de contar historias «más o menos verídicas» (López Sarasúa, 2000: 194) no es algo exclusivamente propio de la primera mitad del siglo $X X$, sino que también de las novelas que cierran el conjunto literario analizado. Así opina la narradora de ¿Qué buscabais en Marrakech? (2000) de sus compañeras de viaje, ambas marroquíes:

Es la primera vez que Hadush me hace reír con tantas ganas. Su forma de narrarlo me lleva al convencimiento de que Aida no lo habría hecho mejor ni en sus disertaciones más logradas (López Sarasúa, 2002: 215).

En un principio, el arte de narrar no tendría por qué ser considerado parte de la trampa perversa de este estereotipo literario, sin embargo, en una narrativa colonial como esta, el capital cultural autóctono puede llegar a ser un obstáculo para la consecución del objetivo perseguido por la metrópoli. Y el peso identitario tiene una indudable impronta de género, las mujeres, no sólo en contextos coloniales, han sido consideradas las transmisoras de este pasado local y de la identidad autóctona ${ }^{9}$. Son

9 Nos refiere Fátima Mernissi que en el Bagdad medieval se identificaba a los cuentacuentos callejeros con instigadores de revueltas y que, por ello, se les prohibió hablar en público (2006: 66). Hay constancia de algo similar en las plazas públicas de las colonias francesas, donde la recitación de historias y cuentos populares estaba prohibida en aras de romper la cadena transmisora de valores tradicionales que, como advierte, por ejemplo, Marta Segarra, sus eslabones principales son las mujeres (1998: 21). 
ellas las que transmiten con sus canciones, con sus cuentos, aquella herencia hurtada por la crónica oficial impuesta y, además, de forma inofensiva. Esto es, como la madre «jugando a jugar, [que] le contaba historias» (López Sarasúa, 2000: 189).

En último lugar, la mujer fatal marroquí es experta en artes amatorias. «Ajenas al trabajo [...] no lo serían al amor, que ya les sonríe en la cuna, pues la musulmana nace exclusivamente para el placer del varón» (Linares Becerra, 1971: 304) y siempre han «sido amantes de los placeres de la carne» (López Sarasúa, 2002: 130). Se acentúa en la otredad femenina marroquí que, reducida a objeto sexual, no sólo acopia los estereotipos de género sino también los de etnia-raza, es la lascivia inherente a la visión occidental sobre el islam: paraíso de huríes y deleites carnales ${ }^{10}$ : «Porque yo te gusto más que todos las huríes que el Profeta te haya prometido para cuando mueras...» (Linares Becerra, 1962: 23). Además, se la representa como una amenaza demográfica, está claro que es ella con su fertilidad feraz la que pare a los moros, denominación habitual dada por las autoras a la población autóctona. Así, se la suele describir activa incluso después de años de matrimonio, siendo sus maridos incapaces de dejarla dado que «ella se lo hacía como se lo hacía» (Cabello, 2000: 116).

Durante aproximadamente la primera mitad del siglo XX esta narrativa colonial es proclive sólo a insinuar los encuentros sexuales entre sus protagonistas. En las descripciones, las autoras optan por reprimir cualquier escena carnal que fuera más allá de un beso o de una suposición nada explícita de lo que acontecería después puertas adentro de la habitación. A causa de ello, sólo cinco de los sesenta y dos relatos y novelas analizados relatan encuentros sexuales a las claras, el resto utiliza la técnica de la elipsis para sortear la cuestión. Por ejemplo, se dan a entender las relaciones sexuales de sus protagonistas con: «... Lo siguiente, suponerlo...» (Ibáñez Blanco, 1956: 289). Sin embargo, en las novelas que cierran el siglo la mujer marroquí, desinhibida, no tiene ningún reparo en «gemir sin rubor alguno» (Cabello, 2000: 12), ni en realizar felaciones (Cabello, 2000: 14), por lo que los detalles sexuales se superponen:

Una mano de Abdelkader fue entonces al pantalón-pijama de ella, entro por su cintura y se zambulló bajo la parte más estrecha de las bragas hasta abrazar sus dedos el clítoris, cuyo meneo tanto le excitaba a él (Cabello, 2000: 12).

La sexualidad desenfrenada hace caer a este personaje femenino marroquí fuera de la racionalidad y, por tanto, en el espacio de la animalidad. De ello resulta que se diga que «era una gata en celo que mimosa se instala en su regazo» (López Sarasúa, 2002: 19), que «se despereza en el asiento con gestos ondulantes de felino» (López Sarasúa, 2002: 31), porque hay en «ella algo de felino cuando trata de acariciarle mimosamente» (Aranda, 1945: 64), tiene «blandos movimientos de gata» (Martín de la Escalera, 1945: 75) y «pudiera convertirse en una pantera» (Ibáñez Blanco, 1956: 146).

Las razones para la vinculación de esta figura literaria marroquí con el gato son dos: por un lado, la imaginería animal que confirma la superioridad española

10 La alusión tan calumniosa como frecuente a la sexualidad y carnalidad del paraíso islámico ha servido para alabar -por contraste dicotómico- el cielo cristiano; éste supuestamente provisto de una moralidad más íntegra no concibe gratificación en el cuerpo sino en el alma. 
y, por otro lado, la felinidad del gato que, habitualmente, ha estado relacionada con el erotismo del cuerpo femenino, sobre todo desde el siglo XIX (Dijkstra, 1986: 288-ss). Tanto es así que en algunas sociedades -como la japonesa- el rótulo de los burdeles es un gato incitador (Durand, 1993: 106). No es digno de sorpresa, ya desde el siglo XV se llamaba a las prostitutas gatas ${ }^{11}$, algo que en el ámbito de esta narrativa colonial preocupada por no consumar las relaciones de intergamia hispano-marroquí, ayudaba a subrayar la prolija fecundidad de la mujer local.

Pero, además, como vemos también se las vincula a las panteras. La mitología lo explica por la belleza de estos animales que ha permitido «cazar a las ovejas por medio de la estrategia de fascinación petrificante: su esplendor suspende a las víctimas en un éxtasis que les conduce a la muerte» (Pedraza, 1983: 152). En efecto, hay muchos precedentes literarios ${ }^{12} \mathrm{y}$ cinematográficos ${ }^{13}$ que recalan en el tándem mujer-pantera como una forma de insistir en la animalidad femenina. Pero, lo más interesante es un dato sobre las panteras que aporta Pilar Pedraza: éstas atraen «a sus víctimas con la belleza de su pelaje y sobre todo con su buen olor» (2009: 87). $\mathrm{El}$ aroma es fundamental en este oriente inventado $\mathrm{y}$, por supuesto, perfumada se encuentra esta mujer fatal que huele a jazmín (Fernández Cubas, 2009: 20), a flores (Fernández Cubas, 2009: 20) y a «sahar» (Aramburu, 1937: 102).

Por último, se vincula a la femme fatale marroquí con las serpientes al decir de ellas que se yerguen como reptiles (Martín de la Escalera, 1945: 66), que son reptantes (Ibáñez Blanco, 1956: 146, 251), sibilinas (Ibáñez Blanco, 1956: 193), se deslizan (Nonell, 1956: 47) o se compara su voz con el «reptar de un ofidio» (Ibáñez Blanco, 1956: 231). También la asociación de las mujeres con las serpientes es habitual en la literatura y en los distintos imaginarios, recordemos a Eva o a la Salambó de Flaubert. Su simbolismo, indefectiblemente, supeditado al mal.

Pues bien, este modelo de mujer de sexualidad activa -al margen de la moral social española del protectorado o el franquismo- sólo tuvo aceptación fronteras afuera de España durante la mayor parte del siglo XX, ya que chocaba de frente con el canon moral imperante que consideraba las pulsiones femeninas antinaturales y sólo entendía la sexualidad bajo esquemas reproductores ${ }^{14}$. Los modelos tradicionales establecidos -divulgados e impuestos por la ideología franquista- optaban por la exaltación de una mujer tradicional, virtuosa, humilde, sencilla, esposa y madre, más cercana al patrón de la virgen María, un ángel, que al de la rebelde Eva, un demonio. En este sentido, esta mujer fatal, sexual y pecadora, era todo lo contrario a lo que se quería promover entre las féminas españolas, asexuadas, santas y asimiladas al canon androcéntrico:

11 Con sus variante gatita o minina. Se dice que reciben esta denominación porque «la gata urbana atrae a muchos gatos cuando está en celo y se aparea con ellos uno tras otro» (Morris, 1998: 114).

12 Pilar Pedraza señala algunas obras como Las diabólicas (1874) de Jules Barbeyd'Aurevilly, Los ojos de la pantera (1897) de Ambrose Bierce u Olalla (1885) de Robert Louis Stevenson.

13 No puedo dejar de señalar la película La mujer pantera de Jacques Tourneur (Estados Unidos, 1942).

14 Después de 1975 este arquetipo literario, y su sexualidad activa, escandaliza cada vez menos en España que va abriendo su mentalidad en consonancia con las democracias europeas más consolidadas. Con todo, es un personaje-tipo que se va desgastando paulatinamente como veremos más adelante y que pervive, sobre todo y de modo subsidiario, en la profesionalización de la femme fatal marroquí. 
En otras palabras, si la mujer debía ser una santa, cualquier mujer no santa, representante de la verdadera feminidad, que tentara a los hombres y los alejaba de lo sagrado y de la pureza era considerada un demonio (Dunn Mascetti, 2008: 160).

Y era considerada un demonio porque desde los modelos patriarcales de la tradición judeo-cristiana se quería bloquear cualquier tipo de capacidad de agencia femenina, entre ellas, también la relativa a la sexualidad y, visto así, esta mujer fatal se rebelaba contra esto en vez de aceptar el rol otorgado. Sin embargo, la representación de esta mujer marroquí no debe ser considerada subversiva en este contexto, no dinamiza ni puede reescribir el canon androcéntrico desde su posición de objeto literario subsidiario. Este personaje femenino marroquí descrita dentro de la dictadura de los cuerpos perfectos -y relegada a la estética de un verdadero club de striptease - es la imagen especular fielmente contrapuesta al estereotipo tradicional del «Ángel del Hogar». Además, este icono estanco, que tanto pábulo le ha dado la tradición judeocristiana, está asentado en dos pilares que este arquetipo literario evade sin remordimientos: madre y esposa abnegada ${ }^{15}$. Nunca se ve a este personaje femenino marroquí representado como madre dedicada ni tampoco como esposa solícita, a pesar de que sí pueda ser una de las esposas del dueño de la casa, ahora bien, en un harén lleno de mujeres tan semidesnudas y lascivas como ella.

Así que, de algún modo, esta mujer marroquí refuerza y se convierte en un vehículo propicio para fortalecer los valores tradicionales. Después de todo, las ficciones no dejan de exaltar -en lo que Zavala ha denominado «propaganda subliminal» (1993: 63- los valores de «esa honra sin tacha, de la que está salpicada la Historia peninsular» (Astray Reguera, 1925: 12) para que las lectoras se identificaran con el icono núbil, respetuoso e íntegro y no con la otredad viciosa y carnal. Gilbert y Gubar lo ven así, «mientras los escritores suelen alabar la sencillez de la paloma, castigan de forma invariable la astucia de la serpiente» (1998: 43).

Veámoslo en un ejemplo, en El convoy de la muerte (1954) el príncipe Yussuf BenOmar quiere convertir a la francesa Ivette en una de las mujeres de su harén pero ésta asegura que ella no es «una mujer fácil, una mujer ligera, abierta a todos los vientos y a todos los caprichos; pronta a vender su cuerpo y sus caricias al mejor postor» (Estévez de Castro, 1954: 21). La joven considera que lo que Ben-Omar quiere de ella, que se deje comprar y forme parte de su séquito sexual, es propio de una muchacha árabe, pero jamás para una francesa como ella, que «sabe respetarse y hacer que la respeten [...] lleva una vida normal, digna y honorable» (Estévez de Castro, 1954: 21).

Así, el Marruecos imaginado por las autoras se convierte, por utilizar la terminología foucaultiana, en un «espacio de las sexualidades ilegítimas» que es mejor «que se vayan con su escándalo a otra parte» (Foucault, 2008: 10); son los llamados espacios de tolerancia como fueron para Foucault el burdel o el manicomio. En este contexto, el orientalismo coloca en oriente todo lo no permitido en occidente, lo cual, de alguna forma, convierte al Marruecos literario en un escenario de tolerancia y transgresión necesaria, es el «otro» constitutivo pero situado en los márgenes.

15 De ahí que algunas autoras, como Marcela Lagarde denominen al Ángel del Hogar como madresposa (1999). 
Visto así, la narrativa española de tema marroquí describe el norte de África exento de esas reglas sociales y morales vigentes en España durante gran parte del siglo XX, porque allí, cruzando el Estrecho, se podía tener cualquier tipo de aventura, también sexual. Se le pedía a la mujer marroquí que fuera artífice de las pulsiones sexuales que la esposa española se negaba a tener. Una apropiación instrumental del cuerpo de la «otra» para desplegar sobre ella todo lo que excede y desestabiliza al «yo». De esta manera, se respetaba el cuerpo de las españolas como el de la madre, esposa -la santafrente al de la mujer marroquí, dispuesta para el esparcimiento de los hombres españoles y válvula de escape para sus mujeres. Por ello, dice un donjuán en las ficciones analizadas que las muchachas marroquíes, todas ellas, incluso las hebreas, son para un ratito. De una en concreto, irónico, asegura que la adoraría «por lo menos durante tres meses» (Rivas, 1949: 37).

Por consiguiente, las autoras del conjunto sometido a estudio han creado -desde una perspectiva tan patriarcal como orientalista- a una vampiresa oriental que despierta la lívido de los «débiles» e «impotentes» hombres a los que domina a través de la instrumentalización de su cuerpo. Los personajes masculinos españoles se sienten atraídos por esta mujer marroquí, suele decirse que han caído en sus redes y que son presas de su seducción, como vaticinando la idea de un fatum. Incluso a veces personificado en Aixa Candixa (López Sarasúa, 2000: 152), un personaje fabuloso al que se le atribuyen poderes sobrenaturales. ${ }^{16}$

De esta forma, es como este personaje literario, atrayente y cautivador, logra arrastrarlos hacia un acantilado, casi como una mantis religiosa, en un eterno femenino cruel de aquellos que históricamente tanto han asustado a los hombres: «Martin y Hernando habían quedado dentro, ya encadenados a la atracción sensual de las danzas» (Villardefrancos, 1953: 93) porque la mujer marroquí «liberaba al caminar una sensualidad salvaje que alertaba a las miradas y las embarullaban» (López Sarasúa, 2002: 130) porque sólo la «luz de sus pupilas traspasaba los corazones como puñales» (Martín de la Escalera, 1945: 76). Las reminiscencias aquí de la Medusa y el papel que ha desempeñado la mirada femenina en la historia cultural occidental es evidente. Así que ante eso el hombre no puede hacer nada, por lo que se conmina en algunos textos al uso de una hamsa-mano de Fátima- para que, a modo de talismán o amuleto, logre que su portador no caiga en las malas tentaciones derivadas de los placeres de la carne (López Sarasúa, 2002: 130). El cuerpo de las mujeres acarrea así un «implacable maleficio» (López Sarasúa, 2002: 130) que, además de demonizar nuevamente a este arquetipo de supuesto origen marroquí, funciona como mecanismo de liberación masculina, al responsabilizarla y culpabilizarla a ella misma de la tentación que despierta en los hombres ${ }^{17}$.

16 También lo he encontrado escrito en la variante Aisha Qandisha y Aicha Kandicha. Según los mitos populares norteafricanos, Aixa Candixa es un demonio femenino inquietante, una hermosa mujer de lascivia salvaje que seduce a los hombres en lugares aislados para después volverlos locos. Para el estudio de Aixa Candixa, véase Cola Alberich, Julio (2005). «Mitos marroquíes: Aicha Kandicha» en Mujeres de marruecos, Editorial El Clan, Madrid, pp.147-151 o Chimenti, Elisa (2005). «Aixa Candixa» en Mujeres de marruecos. Editorial El Clan, Madrid, pp.153-158.

17 Misma ideología patriarcal que ha respaldado diversas sentencias, pongamos por caso España, desde aquella de la Audiencia de Lérida en 1989 -conocida hoy como la «sentencia de la minifalda»donde se consideró que la vestimenta de la joven violada fue la que pudo provocar al acusado. 
Se revela la doble función de la sociedad occidental, que más que decirnos cómo son las mujeres descritas, «nos revela los constructos psicológicos de la psiqué masculina» (Zavala, 1993: 56) que las engendra. En consecuencia, todos estos ardides de la femme fatale marroquí desenmascaran la estrategia de desplazamiento inverso de responsabilidades: es ella la agente de la seducción y malogramiento moral del varón occidental. Por eso, se repite con insistencia que en la mujer marroquí es inherentemente lasciva, que es ella misma la que se ofrece, "¿No me quieres hoy, Sidi?» (Nonell, 1956: 48). Después de todo, si la propia mujer brinda su cuerpo se la puede explotar sin ofensa alguna hacia ella y sin ningún tipo de escrúpulo por parte de él. El hombre queda así liberado y se le dispensa de toda responsabilidad. La depositaria de esta estrategia de apropiación colonial del cuerpo femenino se convierte en estas ficciones, por tanto, en culpable y acusada de su potencial agresión.

\section{La profesionalización de la mujer fatal: el tópico desgastado como contradiscurso}

Son muy pocos los contradiscursos que se encuentran en torno a esta mujer fatal pero los pocos que se hallan son producto del mismo imaginario eurocéntrico. El imaginario orientalista compartido por las autoras las hacía imaginar una «otra» marroquí extremadamente joven, bella, sexual, repleta de joyas, bañada en ricos aromas, embellecida en cosméticos y que cantaba, bailaba y se regalaba a las artes eróticas como única función vital. Un objeto de deseo para la mirada occidental que eleva a la mujer marroquí imaginada desde las expectativas forjadas por el orientalismo romántico. Sin embargo, estas estrategias representacionales colisionan con el orientalismo político interesado en una axiomática menos idílica que mira a Marruecos con ojos más empíricos que embelesados.

En este sentido, expondré las tres prácticas representacionales que me han parecido más significativas, la primera de ellas aparece sobre todo en la novela que inicia la nómina de fuentes primarias, En la guerra (1909) de Carmen de Burgos. La autora no guarda reparos en vapulear la idealizada imagen de la mujer fatal marroquí y, sosteniendo que es debido a la inactividad del harén, la describe como obesa (Burgos, 1989: 211). Nos hallamos en la primera década del siglo XX, cuando el prototipo femenino de belleza en Europa era el de la «Belle Époque», esto es, marcado por la silueta en $S$ a causa del corsé, para conseguir una cintura pequeña y un abdomen plano: lo que unido a la propia corpulencia de Burgos, confirma que esta se hacía eco de un discurso más androcéntrico que personal. Declara, además, que sus «cabelleras tan lindas de lejos, consistían en madejas de algodón negro, dispuestas en largas trenzas, que ocultaban la tiña de sus pelados cascos» (Burgos, 1989: 211). De Burgos lo tiene claro, «[1] as leyendas de su apasionamiento eran tan falsas como la de su belleza» (1989: 210) porque «las moras eran todas feas, deformadas, negras» (1989: 211). El adjetivo «deformada» no es casual, las cree así porque no se atienen a la norma prescrita.

Como vemos, la autora las describe casi escatológicamente, las desmonta del apasionamiento orientalista más romántico y las retrata como portadoras de impurezas y enfermedades, una aproximación política al mismo orientalismo pero 
que mantiene un discurso reduccionista e uniforme del mundo árabe y del islam, caracterizado por polarizaciones entre lo bueno y los buenos, y lo malo y los malos, con generalizaciones excesivas y sin atender, como vemos, a ningún tipo de avance cultural, político o social. Se busca, por tanto, respaldar un único enfoque del mundo que, en definitiva, es el que va a justificar la relación de dominio. Y para ello, no le importa valerse de las distintas aproximaciones orientalistas según conveniencia, dado que debido a las expectativas de corte más romántico y colmadas de imaginación, cuentos y misterio, la caída de la «otra» marroquí como femme fatale es más brutal. No estamos, por tanto, ante una princesa salida de Las mil y una noches sino frente a verdaderas muñecas rotas, incluso calvas, ajenas a toda la estética exótica del harén romántico. Otras novelas posteriores se hacen eco del mismo discurso discriminador como la de Etxezarra (1993), donde se narra una fiesta mora de 1925 en la que la marroquí protagonista no era ni atractiva ni joven, sino «vieja y fea». Los sonidos que deja escapar no son agradables al oído sino «inarticulados, monótonos y sordos y que son de muchísima más resistencia que los oídos de los espectadores» (Charles, 1993: 43). Al final, terminan asegurando que «un rato podría parecer agradable por lo exótica, pero que acaba aturdiendo» (Charles, 1993 43). O, también, la descripción execrable que se hace de una mujer marroquí de mediana edad en un hammam en La llamada del almuédano (1990):

Sus pechos descolgados se mecían al ritmo del monótono balanceo de su cuerpo; las greñas pegadas a la cara y la mirada casi perdida en el vacío le conferían un aspecto fantasmal (López Sarasúa, 2000: 196).

La imagen de la mujer fatal marroquí se aleja esta vez del canon romántico idealizado, casi hasta un límite caricaturesco, porque la aludida ya no es joven, sus senos fláccidos no son atractivos ni desnuda ni vestida (Flavio, 1938: 39) y sus viejos rostros recuerdan a un «higo seco» (Martín de la Escalera, 1945: 169).

De la condena por no ajustarse al molde de lo exótico pasamos en la segunda estrategia seleccionada a la condena de la femme fatale marroquí por intento de emancipación. Lo vemos, por ejemplo, en ¿Qué buscabais en Marrakech? (2000). Esta novela, que cierra la selección de textos analizados, describe la danza de esta figura literaria como un striptease en el que no sólo se quita la ropa como parte del espectáculo, sino que también permite que se la manosee (López Sarasúa, 2002: 174). El baile idealizado de los mitos románticos ya no sólo se realiza por el interés de capturar al hombre que la observa extasiado, sino como fórmula de rentabilización económica del cuerpo de la mujer marroquí al servicio de un sistema de consumo patriarcal.

El personaje de Kensa se sale de esta manera del guion orientalista que la asumía moviendo su vientre y caderas con intenciones únicamente seductoras para situarla en el plano de la realidad más prosaica de la joven que necesita dinero para su propio sustento. Ahora la mujer marroquí quiere una recompensa económica por dejarse mirar, quiere que se la indemnice por siglos de contemplación vouyeurística. Pero por esta causa, por su empoderamiento, por su agencia y por su participación activa en la que podríamos considerar la institución patriarcal más 
antigua, la prostitución, se la condena desde las ficciones. Las autoras españolas que narran Marruecos castigan con el descreimiento más descarnado a la mujer marroquí, dejan entrever su condena a la condición subsidiaria de la prostitución y la colocan en una posición de degradación máxima al servicio de occidente - «se prostituía en un conocido burdel de la ciudad» (López Sarasúa, 2002: 173- y desinflan la descripción mítica de su cuerpo y atractivos. Se ve de forma clara en el retrato de Kensa, cuando ya su cuerpo no está cubierto de gasas es brutal:

El cuerpo de Kensa, casi desnudo no resultaba hermoso. La obesidad había deformado sus caderas y vientre, y el pecho, también enorme, desbordaba generoso del diminuto sostén de encaje negro (López Sarasúa, 2002: 174).

La tercera estrategia seleccionada no censura al arquetipo de femme fatale por no responder a la imagen mental creada desde occidente, como sucedió con el fragmento analizado de Carmen de Burgos. Tampoco se la castiga por sus intentos de agencia o emancipación, como a la Kensa de ¿Qué buscabais en Marrakech? (2000). En esta ocasión, este personaje-tipo es condenado justo porque la ondulación de su cuerpo, el movimiento circular del pañuelo que lleva en su cabeza y el sonido de su figura recargada de oro se han tipificado, casi «profesionalizado» en un embrujo oriental que describen como de pacotilla. La novela de Marisa Villardefrancos recoge el siguiente diálogo entre dos europeos que contemplan a una danzarina en una fiesta:

- ¿Le gusta?

El pintor volvió a él sus ojos claros, su mirada aburrida e ingenua de niño:

No es lo que yo buscaría... Es lo vulgar. El gesto profesional de estas mujeres es el mismo en todas partes.

- Pues entonces..., si no le divierte, vámonos. (1953: 93)

La mirada occidental decide no reparar en el arquetipo, se marcha y cuando sale a la calle agradece el aire fresco de la noche. La femme fatale es tan sólo «espectáculo y comercio» (López Sarasúa, 2002: 143), la princesa de velos y gasas queda mal parada, desvelado su artificio. Sin embargo, con el paso de los años, esa profesionalización de la femme fatale marroquí ya no sólo causa aburrimiento, sino algo peor, risa. La danza sensual de la «otra» marroquí es presentada como un número de un espectáculo para turistas con todo lo que conlleva de superficial y frívolo. Esta imagen arquetípica se convierte en una exhibición teatralizada, que «va incluida en el programa» (López Sarasúa, 2002: 73), lo que es lo mismo, «un montaje destinado a los turistas, uno más de los que suelen organizarse como reclamo» (López Sarasúa, 2002: 74).

Todos aquellos elementos ornamentales que ponían en juego las isotopías narrativas del exotismo y del misterio y que hasta ahora habían servido a la puesta en escena de la femme fatale marroquí se convierten en un atrezo excesivo e insubstancial para aquellos que gustan consumir la diferencia. Los instrumentos, bailes y danzas de la «otra» marroquí forman parte de un «inmenso decorado de cartónpiedra [sic], semejante al montaje de algún pésimo filme americano sobre las Mil y una 
Noches» (López Sarasúa, 2002: 84-5). El retrato que se hace ahora de este arquetipo, a pesar del estudiado juego de luces del escenario, es mucho más crítico, se olvida el exotismo y aparece la simple pantomima:

La tan esperada danza del vientre la interpreta ahora una fornida bailarina, ya entrada en años, cuyas exageradas contorsiones no acaban de adaptarse al ritmo de los músicos (López Sarasúa, 2002: 85).

Ya no se rememora con deleite a una odalisca o bañista turca como la de Ingres, la mirada occidental sólo se detiene en la "cantidad de celulitis» (López Sarasúa, 2002: 85) de la otrora mujer fatal marroquí. Su espectáculo causa la risa, las carcajadas corean las frases de aquellos que la observan y se generan múltiples chistes fáciles: «- ¿Sabéis adónde podríamos mandarla para unos buenos masajes? [...] A Votre Ligne, mujer, aunque dudo que consigan algo si no le rebanan unos cuantos filetes» (López Sarasúa, 2002: 86). Sin embargo, aún puede todo banalizarse más y, de repente, los espectadores -que antes contemplaban a la mujer marroquí- miran hacia el cielo para descubrir lo que calificarán como «colofón verbenero» (López Sarasúa, 2002: 87):

Alguien acaba de atravesar el espacio montado sobre una alfombra, y va desapareciendo lentamente tras los alminares de escayola. ¿Es el profeta o Aladino? (López Sarasúa, 2002: 86).

La mirada occidental se indigna, ya no hay sensación de veracidad, la femme fatale no difiere de la mujer barbuda, forzuda o contorsionista de un espectáculo de circo donde se la exhibe por su discapacidad o enfermedad para el deleite del público. La mujer fatal marroquí no existe, las personas que la esperaban vuelven «enojadas al hotel» (López Sarasúa, 2002: 87) sabiendo que sólo es una mercancía rentable para las agencias de viajes:

La plaza se va quedando sola, inmensa en el sopor que le produce su embriaguez diaria. Poco a poco cae el telón sobre el gran teatro del mundo: fábulas, miseria, hechizo, picardía. Mañana sin falta volverá a representarse la tragicomedia humana (López Sarasúa, 2002: 148).

Basten estos ejemplos para demostrar cómo el imaginario simbólico puede agotarse $y$, a pesar que estas páginas buscan destruir el estereotipo consolidado de la femme fatale a favor de cualquier posibilidad factual de femineidad marroquí, que se desgaste no contribuye al objetivo perseguido. La metanarrativa de alteridad condena a la «otra» marroquí y sus intentos de emancipación y agencia, por lo que, finalmente, decide ni siquiera mirarla, su cliché literario se ha agotado. Ahora bien, el orientalismo fatigado no es un paso hacia la visibilidad, no facilita que emerjan representaciones literarias más fieles de mujeres reales de contextos árabe-islámicos sino que, al contrario, favorece la invisibilización definitiva. O son espectáculo, mito destruido o no son nada. 


\section{A modo de conclusión: el deber de asesinar criaturas literarias}

En el ensayo Yo maté a Sherezade: confesiones de una mujer árabe furiosa (2011) de Joumana Haddad se insiste en la necesidad de matar la femme fatale del imaginario orientalista occidental. Explica como esa Sherezade imaginada por occidente no tiene nada que ver con la oriental, una mujer inteligente, estratégica, intelectual y previsora. Mediante los cuentos consiguió tramar un plan para prolongar su vida que no comprendía, en ningún caso, ofrendar su sexualidad. Sin embargo, la Sherezade occidental, insiste Haddad, atrae más con su cuerpo que con su cerebro y ambiciona aniquilar al hombre en vez de sentarse a negociar con él. Y esa es la imagen que prevalece en el imaginario occidental, tal y como hemos podido comprobar tras el análisis de las fuentes primarias, asumida con total naturalidad e indiferente a los logros obtenidos por las mujeres reales de carne y hueso de ámbito árabe-islámico.

Durante época colonial la interpretación de este arquetipo es especialmente interesante, dado que la mujer marroquí cubierta de pies a cabeza representaba la nación no colonizada, aquella que se defendía como una fortaleza y personificaba el Marruecos inaccesible, abrupto y hostil del orientalismo más político. Y, por el contrario, aunque fuera sólo sobre el papel, la mujer fatal aludía a la conquista. Marruecos podía ser, por ende, el lugar de las bellas mujeres, jóvenes, morenas, repletas de joyas y que bailaban, cantaban y ofrecían sus cuerpos en un escenario de libertad alejado del puritanismo europeo. Sin embargo, nos hallamos ante una narrativa colonial poseedora de una complicidad política que no se puede ignorar. La mujer marroquí debía responder, además, a las necesidades del discurso hegemónico y, éste, durante gran parte del pasado siglo necesitó justificar la colonización. Por consiguiente, este personaje-tipo, como muchos otros arquetipos de la identidad literaria de los personajes marroquíes sirvió para tal fin:

Hay que salvar la mujer mora. En África es un mero instrumento de placer. Mientras no se reivindiquen sus derechos no habrá civilización posible. Mujer y civilización, ambos son femeninas, y como tales, hermanas. Y su destino es paralelo (Villardefrancos, 1953: 15).

Con este breve fragmento de una de las novelas analizadas, una de las autoras revela la actitud interesada e instrumental del occidente eurocéntrico y patriarcal. La misma figura literaria marroquí que desde las fuentes españolas desean ver desnudarse es condenada como víctima sexual de su propia cultura imaginada. No se repara en la contradicción de representarla tentadora y seductora pero, al mismo tiempo, también con "pupilas llenas de un terror salvaje que recordaban los de un animal acorralado» (Villardefrancos, 1953: 8). Las ficciones analizadas están llenas de estos contrasentidos propios de un género ambivalente, así como de símbolos que nunca reflejan un único valor. De ahí que los textos desprendan en todo momento emociones pendulares, sentimientos que oscilan entre el deseo y la compasión, entre el desprecio y la indignación. La femme fatale marroquí, al igual que la mujer completamente cubierta, debía ser redimida por occidente. Una 
porque los hombres la obligan a ir cubierta de pies a cabeza; otra porque es una víctima sexual de los mismos hombres. Sea como fuere, con uno u otro arquetipo -mayoritarios en las tramas- se condena al conjunto de las mujeres marroquíes a una representación literaria subordinada y reduccionista que no coincide con la realidad de ninguna de las mujeres que habitaron y habitan al otro lado del Estrecho.

\section{REFERENCIAS BIBLIOGRÁFICAS}

Aramburu, Rosa de (1937). Ojos largos, Madrid: Editorial Española.

Aranda, Rosa María (1945). Tebib, Zaragoza: Artes Gráficas E. Bermejo Casañal.

Astray Reguera, Margarita (1925). «Pasión de moro» en Los contemporáneos, $\mathrm{N}^{\circ}$ 879, Madrid.

BADE, Patrick (1979). Femme Fatale: Images of Evil and Fascinating Women, London: Ash \& Grant.

BornaY, Erika (1990). Las hijas de Lilith, Madrid: Cátedra.

Burgos, Carmen de (1989). «En la guerra» en Burgos, Carmen de (1989). La flor de la playa y otras novelas cortas, Madrid: Castalia, pp. 163-218.

CABELLo, Encarna (2000). Alizmur, Barcelona: Meteora.

CARrasco GonzÁlez, Antonio (2009). Historia de la novela colonial hispanoafricana, Madrid: Sial.

ChARLes, María (1993). Etxezarra. Barcelona: Anagrama.

Clifford, James (1988). «On Orientalism» en Clifford, James (1988). The Predicament of Culture: Twentieth Century Ethnography, Literature and Art, Cambridge: Harvard University Press, pp. 255-276.

CulLeR, Jonathan (2014). Breve introducción a la teoría literaria, Madrid: Austral.

Dijкstra, Bram (1986). Idols of Perversity: Fantasies of Feminine Evil in Fin-de-Siècle Culture, New York: Oxford University Press.

Dunn Mascetti, Manuela (2008). Diosas, la canción de Eva, Barcelona: Malsinet.

DuRAND, Gilbert (1993). Las estructuras antropológicas del imaginario, Madrid: FCE.

Durango, María Adela (1943). Ojos verdes, Madrid: Pueyo.

Estévez de Castro, Mari Paz (1954). El convoy de la muerte, Pueyo: Madrid.

Fernández CubAs, Cristina (1982). El vendedor de sombras, Barcelona: Alfabia, 2009.

Flavio, Regina (1938?). Alma de Marruecos, Barcelona-Sevilla: Ediciones Betis.

FoucAult, Michel (2008). La voluntad del saber. Historia de la sexualidad I, Argentina: Siglo XXI.

Gilbert, Sandra y Susan Gubar (1998). La loca del desván. La escritora y la imaginación literaria del siglo XIX, Madrid: Cátedra.

HADDAD, Joumana (2011). Yo maté a Sherezade. Confesiones de una mujer árabe furiosa, Barcelona: Debate.

IвÁÑEz Blanco, Blanca (1956). Noche nupcial sin novia, Granada: Imprenta José María Ventura Hita.

Kabbani, Rana (2008). Imperial Fictions. Europe's Myths of Orient, London: Saqi.

Kristeva, Julia (1980). Poderes de la versión, Buenos Aires: Editora. 
LAGARDE, Marcela (1999). Los cautiverios de las mujeres; madresposas, monjas, putas, presas y locas, México DF: UNAM.

LinAREs Becerra, Concha (1941). Cita en el paraíso, Madrid: Imprenta Sáez, 1962, $7^{\mathrm{a}} \mathrm{ed}$.

Linares Becerra, Concha (1942). Muchachas sin besos, Madrid: Cunillera, 1971, $7^{\mathrm{a}}$ ed.

López GARcía, David (1994). El blocao y el oriente: una introducción al estudio de la narrativa del siglo XX de tema marroquí, Madrid: Turner.

López SARAsúA, Concha (1990). La llamada del almuédano, Alicante: Cálamo, 2000, $3^{\mathrm{a}} \mathrm{ed}$.

López Sarasúa, Concha (2001). ¿Qué buscabais en Marrakech? Alicante: Cálamo, 2002, $2^{\mathrm{a}}$ ed.

Martín-Márquez, Susan (2011). Desorientaciones. El colonialismo español en África y la performance de identidad, Barcelona: Bellaterra.

Martin de la Escalera, Carmen (1945). Fatma. Cuentos de mujeres marroquíes, Madrid: Publicaciones África. Instituto de Estudios Políticos.

Mernissi, Fátima (2006). El harén en Occidente, Madrid: Espasa Calpe.

Morris, Desmond (1988). Observe a su gato, Barcelona: Plaza \& Janés.

Nonell, Carmen (1956). Zoco grande, Madrid: Colenda.

Pedraza, Pilar (2009). Venus barbuda y el eslabón perdido, Madrid: Siruela.

PedrazA, Pilar (1983). La Bella, enigma y pesadilla. Valencia: Almudín.

Propp, Vladimir (1998). Morfología del cuento, Madrid: Akal, 2014, $4^{\mathrm{a}}$ ed.

Rivas, Josefina (1949). Noches de Tánger, Barcelona: Bruguera.

SAID, Edward W. (1996). Representaciones del intelectual, Barcelona: Paidós.

SAID, Edward W. (2003). Orientalismo, Barcelona: Debolsillo.

SAID, Edward W. (2012). Cultura e imperialismo, Barcelona: Anagrama.

SEgARRA, Marta (1998). «¿Lengua del colonizador o lengua colonizada?» en SEgARRA, Marta (1998). Mujeres magrebies. La voz y la mirada en la literatura norteafricana, Barcelona: Icaria, pp. 17-28.

Villardefrancos, Marisa (1953). El sol nace de madrugada, Madrid: Biblioteca de Chicas.

ViÑuelas, María (1946). Los vencidos, Madrid: Aguilar.

Woolf, Virginia (2010). «Profesiones para mujeres» en La muerte de la polilla y otros escritos, Madrid: Capitán Swing, pp. 211-219.

ZavAlA, Iris M. (1993). «Las formas y funciones de una teoría crítica feminista. Feminismo dialógico» en Díaz-Diocaretz, Myriam e Iris M. Zavala (ed.) (1993). Breve historia feminista de la literatura española (en lengua castellana), Madrid: Anthropos, pp. 27-76.

Recibido el 24 de febrero de 2018

Aceptado el 15 de mayo de 2018

BIBLID [1132-8231 (2018): 277-293] 